\title{
Does Fever Relieve Autistic Behavior by Improving Brain Blood Flow?
}

\author{
Peter Good
}

Received: 5 January 2011 / Accepted: 6 January 2011 / Published online: 20 January 2011

(C) Springer Science+Business Media, LLC 2011

Helt and coworkers (Helt et al. 2008) reported that significant fevers have improved autistic behavior, citing the sole controlled study (Curran et al. 2007). This study was prompted by anecdotal reports (Sullivan 1980; Cotterill 1985; Brown 1999) of dramatic improvements in social interaction and speech-core deficits of autismduring fever. Informal parent surveys indicate that fever benefits $30-40 \%$ of autistic children (Simons Foundation 2010). Helt et al pointed out that confirming fever's ability to stimulate emotional contact and speech would be especially meaningful. They noted reports of low brain blood flow in these children, and proposed an intriguing explanation-swollen astrocytes compressing brain capillaries.

Implicit in this evidence is a simple argument: In a disorder characterized by low brain blood flow, can high-level cortical functions like speech and social interaction become almost normal without more blood to the brain? Fever increases cerebral blood flow (CBF) for nutrients and cooling, which can improve well-being and performance in persons whose cerebral circulation is compromised (Kiyatkin 2010). The obvious inference is that fever may improve speech and social behavior in autistic children largely by increasing brain blood flow.

The benefit of fever in autism was the focus of a recent workshop (Simons Foundation 2010). The effect of temperature to increase $\mathrm{CBF}$ was considered, but

Letter re: Helt et al. 2008. Can children with autism recover? If so, how? Neuropsychology Review, 18(4), 339-366.

P. Good $(\bowtie)$

Autism Studies,

PO Box 1683, LaPine, OR 97739, USA

e-mail: petergood1@mac.com discounted because a sauna or hot tub doesn't usually help (Miles 2010). The best explanation may be that fever increases brain temperature much more than ambient heat (Kiyatkin 2010): "In contrast [to fever], sauna or environmental warming affects brain temperature very little, especially in humans, because of sophisticated homeostatic mechanisms that maintain stability of body temperature.... While data in humans are limited, it appears that fluctuations due to stress, environmental warming, etc. are relatively weak (up to $1.0-1.5^{\circ} \mathrm{C}$ ), but during fever this increase is much larger, especially in children." The benefit of fever in autistic children appears to reach a maximum at elevations of $1.5-2.5^{\circ} \mathrm{C}$ (Cotterill 1985).

One homeostatic mechanism that prevents brain hyperthermia from ambient heat or stress is elevation of GABA in interstitial fluid; fever, by contrast, reduces GABA, and elevates the free amino acid taurine (Frosini 2007). Blood GABA appears high in autistic children (Dhossche et al. 2002), brain GABA may be downregulated (Harada et al. 2010; Hasler et al. 2010); taurine is often depleted (Pangborn 2002). Downregulation of GABA elevates brain temperature therefore blood flow, but fever's elevation of taurine may be more decisive because taurine carries water out of swollen astrocytes (Benarroch 2005). Various neurotoxins implicated in autism (e.g. ammonia, excess glutamine, organic mercury) cause astrocytes to swell, which can compress the lumen of brain capillaries by nearly half (Aschner et al. 1999) If swollen astrocytes compress brain capillaries in autism spectrum disorders, as Helt et al. suggested, elevation of taurine by fever may decompress these vessels and improve CBF. Taurine may also increase brain blood flow by suppressing release of GABA by neurons (Kuriyama and Hashimoto 1998). Autistic children who do not improve during fever may be those most depleted of taurine. 


\section{References}

Aschner, M., Allen, J. W., Kimelberg, H. K., LoPachin, R. M., \& Streit, W. J. (1999). Glial cells in neurotoxicity development. Annual Review of Pharmacology and Toxicology, 39, 151-173.

Benarroch, E. E. (2005). Neuron-astrocyte interactions: partnership for normal function and disease in the central nervous system. Mayo Clinic Proceedings, 80(10), 1326-1338.

Brown, G. (1999). The sometimes son. The Humanist, 59(1), 46-47.

Cotterill, R. M. J. (1985). Fever in autistics. Nature, 313(6002), 426.

Curran, L. K., Newschaffer, C. J., Lee, L. C., Crawford, S. O., Johnston, M. V., \& Zimmerman, A. W. (2007). Behaviors associated with fever in children with autism spectrum disorders. Pediatrics, 120(6), e1386-e1392.

Dhossche, D., Applegate, H., Abraham, A., Maertens, P., Bland, L., Bencsath, A., et al. (2002). Elevated plasma gamma-aminobutyric acid (GABA) levels in autistic youngsters: stimulus for a GABA hypothesis of autism. Medical Science Monitor, 8(8), PR1-PR6.

Frosini, M. (2007). Changes in CSF composition during heat stress and fever in conscious rabbits. Progress in Brain Research, 162, $451-460$

Harada, M., Taki, M. M., Nose, A., Kubo, H., Mori, K., Nishitani, H., et al. (2010). Non-invasive evaluation of the GABAergic/ glutamatergic system in autistic patients observed by MEGA- editing proton MR spectroscopy using a clinical 3 Tesla instrument. Journal of Autism and Developmental Disorders. epub 2010 Jul 21.

Hasler, G., van der Veen, J. W., Grillon, C., Drevets, W. C., \& Shen, J. (2010). Effect of acute psychological stress on prefrontal GABA concentration determined by proton magnetic resonance spectroscopy. The American Journal of Psychiatry, 167(10), 1226-1231.

Helt, M., Kelley, E., Kinsbourne, M., Pandey, J., Boorstein, H., Herbert, M., et al. (2008). Can children with autism recover? If so, how? Neuropsychology Review, 18(4), 339-366.

Kiyatkin, E. A. (2010). Personal communication.

Kuriyama, K., \& Hashimoto, T. (1998). Interrelationship between taurine and GABA. Advances in Experimental Medicine and Biology, 442, 329-337.

Miles, J. (2010). Personal communication.

Pangborn, J. B. (2002). Introduction to the diseases of autism and laboratory testing options. In J. B. Pangborn \& S. M. Baker (Eds.), Biomedical assessment options for children with autism and related problems (pp. 1-130). San Diego: Autism Research Institute.

Simons Foundation. Workshop report: Fever and autism. https://sfari. org/workshop-reports/-/asset_publisher/lVf7/content/workshopreport-fever-and-autism? redirect $=\% 2 \mathrm{Fw}$ orkshop-reports (Accessed 11/30/10).

Sullivan, R. C. (1980). Why do autistic children...? Journal of Autism and Developmental Disorders, 10(2), 231-242. 